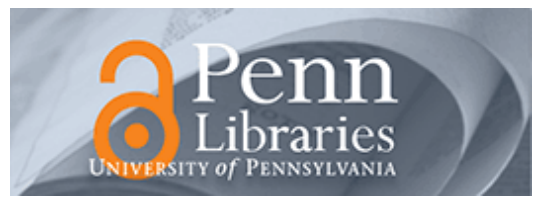

University of Pennsylvania ScholarlyCommons

$1-2007$

\title{
Regionalization Versus Competition in Complex Cancer Surgery
}

Vivian Ho

Robert J Town

University of Pennsylvania

Martin J Heslin

Follow this and additional works at: https://repository.upenn.edu/hcmg_papers

Part of the Medical Education Commons, Other Medical Sciences Commons, Surgery Commons, and the Surgical Procedures, Operative Commons

\section{Recommended Citation}

Ho, V., Town, R., \& Heslin, M. (2007). Regionalization Versus Competition in Complex Cancer Surgery. Health Economics, Policy and Law, 2 (1), 51-71. http://dx.doi.org/10.1017/S1744133106006256

At the time of publication, author Robert J. Town was affiliated with the University of Minnesota. Currently, he is a faculty member at the Wharton School at the University of Pennsylvania.

This paper is posted at ScholarlyCommons. https://repository.upenn.edu/hcmg_papers/143

For more information, please contact repository@pobox.upenn.edu. 


\title{
Regionalization Versus Competition in Complex Cancer Surgery
}

\begin{abstract}
The empirical association between high hospital procedure volume and lower mortality rates has led to recommendations for the regionalization of complex surgical procedures. While regionalization may improve outcomes, it also reduces market competition, which has been found to lower prices and improve health care quality. This study estimates the potential net benefits of regionalizing the Whipple surgery for pancreatic cancer patients. We confirm that increased hospital volume and surgeon volume are associated with lower inpatient mortality rates. We then predict the price and outcome consequences of concentrating Whipple surgery at hospitals that perform at least two, four, and six procedures respectively per year. Our consumer surplus calculations suggest that regionalization can increase consumer surplus, but potential price increases extract over half of the value of reduced deaths from regionalization. We reach three conclusions. First, regionalization can increase consumer surplus, but the benefits may be substantially less than implied by examining only the outcome side of the equation. Second, modest changes in outcomes due to regionalization may lead to decreases in consumer surplus. Third, before any regionalization policy is implemented, a deep and precise understanding of the nature of both outcome/volume and price/competition relationships is needed.
\end{abstract}

\section{Keywords}

outcome assessment, economic competition, quality of health care, cancer surgery, volume outcome

\section{Disciplines}

Medical Education | Other Medical Sciences | Surgery | Surgical Procedures, Operative

\section{Comments}

At the time of publication, author Robert J. Town was affiliated with the University of Minnesota. Currently, he is a faculty member at the Wharton School at the University of Pennsylvania. 


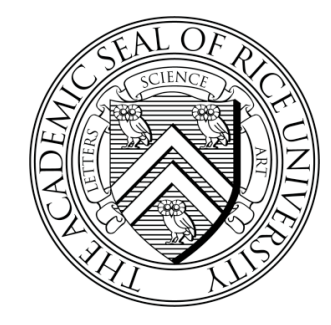

The James A. Baker III Institute for Public Policy RICE UNIVERSITY

\title{
REgIONALIZATION VERSUS COMPETITION in COMplex CANCER SURGery
}

\author{
BY \\ Vivian Ho, PhD \\ James A. BAKer III InStitute For Public POlicy, Rice University \\ and Department of Medicine, Baylor College of Medicine \\ Robert J. TOWN, PhD \\ SCHOOL OF PUblic HeALTH, \\ UNIVERSITY OF MINNESOTA \\ AND \\ MARTIN J. HesLin, MD \\ DEPARTMENT OF SURGERY, \\ THE UNIVERSITY OF AlabAMA AT Birmingham
}

MARCH 2007 


\section{Regionalization Versus Competition in Complex Cancer Surgery}

THESE PAPERS WERE WRITTEN BY A RESEARCHER (OR RESEARCHERS) WHO PARTICIPATED IN A

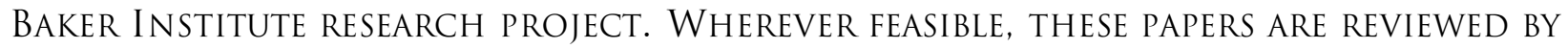
OUTSIDE EXPERTS BEFORE THEY ARE RELEASED. HOWEVER, THE RESEARCH AND VIEWS EXPRESSED IN THESE PAPERS ARE THOSE OF THE INDIVIDUAL RESEARCHER(S), AND DO NOT NECESSARILY represent the Views of the James A. Baker III Institute for Public Policy.

THIS PAPER HAS BEEN ACCEPTED FOR PUBLICATION AND APPEARS IN A REVISED FORM, AFTER editorial in put by CAmbridge University Press, in HEALTH ECONOMICS, POliCy AND LAW PUblished by CAMbridge UNIVERSITY PRESS. NO FURTHER RePRODUCTION OF THIS MATERIAL is ALLOWED WITHOUT THE PERMISSION OF CAMBRIDGE UNIVERSITY PRESS: SEE HTTP://WWW.CAMBRIDGE.ORG/UK/INFORMATION/RIGHTS/.

Health Economics, Policy and Law, 2, 01(2007), 51-71.

(C) Cambridge University Press 2007

http://www.cambridge.org/journals/journal catalogue.asp?mnemonic=HEP

THIS RESEARCH WAS SUPPORTED BY GRANT NUMBER RSGHP-03-076-01-PBP FROM THE american Cancer Society. We are grateful to Hal luft, mark Pauly, and seminar PARTICIPANTS AT THE 14TH AHEC CONFERENCE AT RAND AND AT THE 5TH IHEA WORLD CONGRESS FOR HELPFUL COMMENTS ON AN EARLIER DRAFT OF THIS PAPER. 


\title{
Regionalization Versus Competition in Complex Cancer Surgery
}

\begin{abstract}
The empirical association between high hospital procedure volume and lower mortality rates has led to recommendations for the regionalization of complex surgical procedures. While regionalization may improve outcomes, it also reduces market competition, which has been found to lower prices and improve health care quality. This study estimates the potential net benefits of regionalizing the Whipple surgery for pancreatic cancer patients. We confirm that increased hospital volume and surgeon volume are associated with lower inpatient mortality rates. We then predict the price and outcome consequences of concentrating Whipple surgery at hospitals that perform at least 2, 4 and 6 procedures respectively per year. Our consumer surplus calculations suggest that regionalization can increase consumer surplus, but potential price increases extract over half of the value of reduced deaths from regionalization. We reach three conclusions. First, regionalization can increase consumer surplus, but the benefits may be substantially less than implied by examining only the outcome side of the equation. Second, modest changes in outcomes due to regionalization may lead to decreases in consumer surplus. Third, before any regionalization policy is implemented, a deep and precise understanding of the nature of both outcome/volume and price/competition relationships is needed.
\end{abstract}

Keywords: outcome assessment; economic competition; quality of health care; cancer surgery; volume outcome.

JEL codes: I100, L400, L500

\section{INTRODUCTION}

Hospitals performing a higher number of surgical procedures tend to have better outcomes. This relation has been identified for a number of procedures, including coronary artery bypass graft surgery, hip fracture surgery, coronary angioplasty, and eight major types of cancer resection (Birkmeyer et al., 2002; Gaynor et al., 2005; Hughes et al., 1988; Luft et al., 1979; Phillips et al., 1995). These findings have led several researchers and policy makers to recommend regionalization of complex surgeries. Proponents of regionalization argue that concentrating surgery at a few 


\section{Regionalization Versus Competition in Complex Cancer Surgery}

geographically dispersed high-volume facilities and eliminating low-volume providers will lead to improved patient outcomes and lower costs.

However, there is a large literature that documents that competition lowers hospital prices paid by health insurers (Capps et al., 2004; Gaynor et al., 2004). Another, smaller branch of the literature finds that competition among hospitals can lead to improved outcomes and/or lower patient costs (Kessler et al., 2000). Thus, regionalization could stifle the potential benefits of competition. The impact of regionalization on patients and consumers will depend upon which effect dominates -- the value of the reduction in mortality due to increased volume, or the increase in prices due to consolidation of providers. The tension between the efficiencies of consolidation and the loss of consumer surplus due to increased prices has a long history in the industrial organization literature (Williamson, 1968). However, these issues have not been explicitly addressed in the hospital competition literature. ${ }^{1}$

This manuscript uses the Whipple procedure as a case study to examine the potential benefits of regionalization versus competition in complex cancer surgery to consumers. Whipple surgery is an excellent procedure to perform this analysis, because past studies suggest that regionalization of this procedure would lead to large reductions in mortality. We focus on the consumer surplus consequences instead of calculating the total welfare impact of regionalization for three reasons. First, it is our sense that it would be difficult to advocate for the regionalization of procedures unless consumers were to benefit. A policy that increased hospital profits at the expense of patient welfare will not likely be popular. Second, our data does not contain enough information to perform the cost and profit margin calculations necessary to measure producer surplus without making additional strong assumptions. Third, total welfare will decline only if the number of procedures declines because of an increase in price. Most complex procedures are covered by health insurance, and it is unlikely that price increases due to regionalization will lead to enough of an increase in health insurance premiums to meaningfully impact the percent of the population that has health insurance coverage. That is, if there are outcome benefits from regionalization, then it will almost certainly be total welfare improving. The more interesting question is: How are those welfare benefits distributed

\footnotetext{
${ }^{1}$ The paper that is closest in spirit to ours is Huckman (2006). He estimates the impact on mortality and costs of larger hospitals acquiring smaller hospitals. However, he does not attempt to quantify the price impact of
} 


\section{Regionalization Versus Competition in Complex Cancer Surgery}

between hospitals and patients?

Using patient-level hospital discharge data from Florida, New Jersey, and New York, we estimate the impact of increasing provider (hospital and surgeon) volume and market concentration on patient mortality. Consistent with the previous literature we find that an increase in volume substantially and significantly reduces in-hospital mortality. For example, a doubling of hospital volume from 5 to 10 procedures per year reduces mortality by 5 percent. This suggests that the consolidation of procedures will increase the quality of patient outcomes. The analysis also yields no evidence that greater competition improves patient outcomes.

Given the parameter estimates from the mortality analysis and estimates of the price concentration relationship from the literature, we then explore the welfare impact of regionalizing the Whipple procedure in three different policy experiments. In these experiments, we move those patients at hospitals performing fewer than a given number of procedures to the nearest hospital performing at least that number of surgeries in a given year. The cut-offs are 2, 4 and 6 procedures.

In these experiments expected mortality declines from between 0.5 and 3.1 percentage points. This is a substantial improvement in outcomes that is expected to raise the average value of the procedure (measured using the value of a QALY) between $\$ 500$ and $\$ 3,100$ per patient. However, regionalization increases concentration significantly. The Herfindahl index for Whipple surgery increases by .02 to .33 based on the regionalization rule. Based on an estimate of the average price of Whipple surgery from an external source and results from the previous literature on hospital competition, increases in concentration implied by the policy experiment are estimated to increase prices by between $\$ 1,142$ and $\$ 1,932$. That is, on average regionalization increases welfare; but consumers gain less than half of that improvement. In fact, in one of our experiments, consumer surplus declined.

Our analysis suggests the following policy implications regarding the diffusion of new technologies and the consolidation of procedures. First, it suggests that government efforts to reduce the proliferation of providers performing new, complex procedures can increase consumer welfare. 


\section{Regionalization Versus Competition in Complex Cancer Surgery}

However, unless price competition is preserved, consumer surplus may increase substantially less than suggested by analyzing the improvement in outcomes alone. Second, the devil is in the details. The benefits of regionalization will be sensitive to the estimates of the impact of volume on outcomes and, importantly, on the exact nature of the price competition relationship. Thus, before any regionalization policy is implemented a deep and precise understanding of the nature of both outcome/volume and price/competition relationships is needed. In our view, the literature on hospital competition analysis has probably not yet advanced to that point.

\section{BACKGROUND AND LITERATURE REVIEW}

The Whipple procedure is a surgical procedure for patients with localized pancreatic cancer, extrahepatic bile duct cancer, or cancer of the small intestine. The operation is complex, requiring removal of the head of the pancreas, part of the small intestine, and some of the tissues around it. Although the inpatient mortality rate for the Whipple procedure is relatively high, it is considered to be the most effective method for treating early stage pancreatic cancer. Many patients are willing to accept this surgical risk, because 5-year survival rates for early stage pancreatic cancer are low. ${ }^{2}$

Past studies from the medical literature have found that both hospitals and surgeons that perform more Whipple surgeries in a given year have lower mortality rates (Birkmeyer et al., 1999; Ho et al., 2002). Many researchers believe that this volume-outcome relation reflects "practice makes perfect" or "learning by doing" (Luft et al., 1979; Sturm, 1999). Providers who perform more surgeries gain experience which leads to improved future outcomes. In the context of Whipple surgery, more experienced surgeons may have improved dexterity, or achieve shorter operating times that lower blood loss during surgery. Learning may enable hospitals to develop routines for preventing or treating life threatening complications after surgery.

Although many researchers would interpret a negative association between annual provider volume and mortality rates as a learning effect, one cannot rule out the possibility that the relation reflects organizational scale effects. The volume-outcome effect may be attributable to the specialized staff, facilities, and equipment which are more likely to be present at high-volume centers (Gordon et al.,

\footnotetext{
2 The overall survival rate for pancreatic cancer is $4 \%$. The 5 -year survival rate for patients undergoing complete surgical resection has been estimated to be $18 \%$ to $24 \%$.
} 


\section{Regionalization Versus Competition in Complex Cancer Surgery}

1999). For this reason, economists have used cumulative production as a measure of learning effects, and annual production as measure of organizational scale effects (Spence, 1981; Sturm, 1999). For example, one could argue that for a patient being treated in 1996, the total number of Whipple procedures ever performed by the operating surgeon prior to 1996 is a more accurate measure of learning than the number of procedures performed by that surgeon in 1996 alone.

Technical change represents improvements in production quality or efficiency occurring over time, which are independent of current output (Solow, 1957). These improvements may result from the sharing of information at national conferences, in medical journals, or the transfer of experienced personnel across facilities. Technological change may also result from the development of new surgical technologies which medical device makers diffuse quickly amongst providers. Reductions in mortality over time after complex medical treatment have been attributed to technical change in past studies (Cutler et al., 2001; Ho V., 2002).

The literature on the relationship between increased provider volume and lower mortality rates have led to recommendations for regionalization of complex surgeries; concentrating these procedures at a few geographically-dispersed facilities will lead to higher average provider volume and therefore better outcomes. This opinion has been voiced in editorials in the medical literature, by the Leapfrog Group, and also by some panelists at the joint hearings of the Department of Justice and Federal Trade Commission to improve health care (Department of Justice et al., 2004). These recommendations for regionalizaton have been made, in spite of the fact that very little empirical evidence is available on the effects of actual market consolidation on patient outcomes (Ho V. et al., 2000; Wong et al., 2004).

Yet regionalization would reduce the number of providers performing surgery and therefore the amount of competition in local health care markets. Economic theory suggests that the predicted effect of hospital competition on quality of care is ambiguous in a market like that for the Whipple procedure, where most prices are administered by either Medicare or private insurers (Pauly, 2004). Fixed prices may lead hospitals to compete for patients by offering higher quality. However, administered prices may also lead high price/high quality providers to exit the market, lowering average quality. 


\section{Regionalization Versus Competition in Complex Cancer Surgery}

Empirical evidence suggests that increased hospital competition led to improved outcomes and lower costs for Medicare patients suffering from heart attack (Kessler et al., 2000). Another study of California patients finds that increased hospital competition reduced inpatient mortality for pneumonia and heart attack patients covered by HMOs, but increases mortality for Medicare patients (Gowrisankaran et al., 2003). Despite the potential offsetting effects of regionalization versus competition on hospital outcomes, no study has simultaneously analyzed the effects of each of these factors on hospital mortality rates. In addition, regionalization ignores the fact that technological change in the national market may also improve outcomes for complex surgeries. In the next section, we outline our approach to identifying these effects in the care of Whipple surgery.

\section{MODEL SPECIFICATION}

We draw upon more general studies of learning by doing, as well as more specific studies of hospital competition and volume-outcome effects to specify a model of the determinants of inpatient mortality:

$$
\operatorname{Died}_{i s h t}=f\left(\text { AnnVol }_{h t}, \text { AnnVol }_{s t}, \text { Herf }_{r t}, \text { Year }_{t}, \text { Casemix }_{i t}, \theta_{h}\right)
$$

where Died $_{\text {ihst }}=1$ if patient $i$ treated in hospital $h$ by surgeon $s$ in year $t$ died in hospital, and 0 otherwise. AnnVol ${ }_{h t}$ is the number of Whipple procedures performed in year $t$ in hospital $h$, and $\mathrm{AnnVol}_{s t}$ represents procedure volume at the surgeon level. As mentioned previously, these annual volume measures have been hypothesized to capture a learning by doing effect.

We initially estimated equation (1) including both annual and cumulative measures of procedure volume. However, the correlation between annual and cumulative hospital volume is 0.95 ; and the correlation between annual and cumulative surgeon volume is 0.84 . This high correlation suggests that high-volume providers tend to remain large throughout the sample period, and low-volume providers tend to remain small. Preliminary estimates of equation (1) including both cumulative and annual measures of volume led to unstable regression estimates. This same pattern of multicollinearity was encountered in a previous study of the volume-outcome relation for coronary angioplasty (Ho V., 2002). Therefore, we estimate equation (1) with only annual measures of 


\section{Regionalization Versus Competition in Complex Cancer Surgery}

procedure volume in this study. ${ }^{3}$ The multicollinearity between annual and cumulative measures of Whipple procedure volume prevents us from separately identifying the effects of learning by doing versus organizational scale. ${ }^{4}$

Equation (1) will test the hypothesis that competition influences outcomes for the Whipple procedure by examining the association between local market concentration $\left(\operatorname{Herf}_{r t}\right)$ and mortality rates. Market concentration is measured using a Herfindahl index based on each hospital=s share of patients undergoing the Whipple procedure in a hospital referral region (HRR). ${ }^{5}$ Year effects are included in equation (1) to control for potential technological progress.

Patient-specific casemix variables are included to control for disease severity. These variables include patient age, gender, indicator variables for the 8 conditions that comprise the Charlson comorbidity index ${ }^{6}$ and dummy variables distinguishing the 5 indications for Whipple surgery. ${ }^{7}$ Length of stay is included in the inpatient mortality equation, because one is more likely to observe in-hospital death for patients who have longer hospitalizations. ${ }^{8}$ Indicator variables for whether or not the patient was admitted to a teaching hospital, as well as dummy variables for Florida and New

${ }^{3}$ We chose to estimate the regressions with annual volume, because it straightforward to simulate policy interventions that redirect patients to hospitals based on each facilities' annual volume. If we were to repeat the simulations using cumulative volume, the results would be similar, because annual and cumulative volume are so highly correlated. However, annual volume is an easier concept for policy makers to grasp.

4 Alternative solutions to the multicollinearity problem are not satisfactory or feasible for this study. A ridge regression estimator would yield biased estimates of the learning effect. A principal components specification based on linear combinations of the original explanatory variables would not yield coefficients which are readily interpretable as learning (Greene W.H., 2000). An alternative measure of learning by doing which is uncorrelated with annual procedure volume is necessary to resolve this issue (Goldberger, 1991; Wooldridge, 2000). We have been unable to identify an alternative measure and reserve this issue for future research.

${ }^{5}$ Hospital referral regions represent regional health care markets for tertiary medical care. These regions are defined by aggregating zip codes, then local health care markets where Medicare patients receive most of their care from hospitals within that area. There are 306 hospital referral regions in the U.S. ranging in population in 1996 from 126,329 to $9,288,694$.

6 These comorbidities are: a previous myocardial infarction, peripheral vascular disease, chronic pulmonary disease, mild liver disease, mild to moderate diabetes, diabetes with chronic complications, renal disease, and moderate or severe liver disease.

${ }^{7}$ The 5 indications for surgery are: pancreatic cancer, extra-hepatic bile duct cancer, duodenal cancer, benign pancreatic disease, and other diagnoses. Patients receiving the Whipple surgery due to trauma are excluded from the sample.

${ }^{8}$ We also estimated the inpatient mortality regression excluding length of stay as an explanatory variable. The coefficients on all of the volume variables remained the same to the second decimal point. These results are available from the authors upon request. 


\section{Regionalization Versus Competition in Complex Cancer Surgery}

Jersey patients were included in equation (1). Patient mortality is also hypothesized to depend on a vector of unobserved hospital characteristics $\theta_{h}$.

Equation (1) is estimated including linear terms for each of the procedure volume variables. Quadratic terms for each of the volume variables are included in the reported specification if they were precisely estimated in preliminary estimates. Preliminary estimates also included interactions of provider volume with a state dummy variable. We hypothesized that the volume-outcome relation might vary due to potential differences in coding of the hospital discharge abstracts by state. For example, although we control for casemix differences in the regressions, differences in the propensity to code comorbidities might influence the volume-outcome relationship. These interaction terms were included in the reported specification if they were precisely estimated.

Equation (1) is estimated as a panel data, multilevel logit random effects model to adjust for the clustering of patients within surgeons and the clustering of surgeons within hospitals. Surgeons who performed the same procedure in more than one hospital in one year ( $7.3 \%$ of all surgeons) were modeled as contributing a separate random effect in each hospital where they treated patients. We conducted a Hausman test to determine whether hospital-level fixed effects would be necessary in Equation (1) to obtain consistent estimates (Hausman, 1978). We could not reject the null hypothesis that the multilevel random effects specification yields both consistent and efficient estimates $\left(\chi^{2}(33)=33.21, p=0.46\right)$. We therefore report random effects estimates for the determinants of hospital mortality. ${ }^{9}$

\section{Calculating Consumer Surplus Effects of Regionalization}

In our consumer surplus calculation we assume that insurers reimburse hospitals for Whipple surgery. However, insurers pass the full cost of price increases for non-Medicare patients along to consumers in the form of higher premiums. The expected consumer surplus that potential patients receive from a procedure if they have health insurance can be written as:

\footnotetext{
${ }^{9}$ Researchers are experimenting with a maximum likelihood approach to estimating the volume-outcome relation for the Whipple procedure, using distance to the hospital as an instrument for hospital selection. This approach should yield more precise standard errors when controlling for unobserved patient heterogeneity. Preliminary results suggest that the volume-outcome relation is attenuated when one controls for unobserved heterogeneity in this manner (Gowrisankaran et al., 2006). If so, then the random effects estimates provide upper bound estimates of the benefits of regionalization.
} 


\section{Regionalization Versus Competition in Complex Cancer Surgery}

$$
C S_{h i}=V_{i h}\left(S_{i}=1\right) \operatorname{Pr}\left(S_{i}=1\right)-P_{h} \operatorname{Pr}\left(S_{i}=1\right)
$$

where $V_{i h}\left(S_{i}=1\right)$ is the expected value of the procedure (net of transportation costs) performed at hospital $h$ on individual $i$ conditional on benefiting from the procedure, $S_{i}$ is the indicator that the patient is sick and therefore would benefit from the procedure, $P_{h}$ is the price of the procedure, and $\operatorname{Pr}\left(S_{i}=1\right)$ is the probability that an individual is sick with the condition. The first term is simply the expected value of the benefit that a patient receives from the procedure, and the second term is the actuarially fair cost of the procedure to the insured pool. Without loss of generality, we are assuming that the probability of benefiting after falling ill is the same for all in the insurance pool.

The change in consumer surplus associated with a regionalization policy is then,

$$
\Delta C S_{h i}=\left(\Delta V_{i h}-\Delta P_{h}\right) \operatorname{Pr}\left(S_{i}=1\right)+\left(V_{\text {ih }}^{\text {New }}-P_{h}^{\text {New }}\right) \Delta \operatorname{Pr}\left(S_{i}=1\right)
$$

The first term is the expected value of the procedure minus its impact on premiums. The second term captures the possibility that either the new price or quality of care after regionalization influences the probability of electing surgery. Here the superscript New denotes the post-regionalization quality of care and prices. In our analysis we assume that $\Delta \operatorname{Pr}\left(S_{i}=1\right)=0$, which is probably reasonable. Although inpatient mortality is likely to be lower after regionalization, the procedure remains highly risky. Therefore, doctors will continue to refer patients for surgery based on their clinical prognosis rather than marginal changes in the quality of care. In addition, insured patients who have reached this stage of treatment are likely to be relatively insensitive to price increases when deciding whether to undergo surgery. Assuming $\Delta \operatorname{Pr}\left(S_{i}=1\right)=0$ implies that the consumer surplus impact of increasing volume simply turns on whether the mortality benefits to patients outweigh the pricing consequences of the increased market power.

With the estimates of the mortality equation in hand we perform three policy experiments. The three policy experiments involve "closing" hospitals whose current volume is below a threshold and moving patients who were admitted to the closed hospital to the closest hospital above the threshold. We then calculate the expected change in mortality and change in concentration due to these regionalization policies. The three experiments use three different closure thresholds: $<2$ annual procedures, $<4$ annual procedures and $<6$ annual procedures. These cut-offs approximate the $15^{\text {th }}$, $30^{\text {th }}$, and $40^{\text {th }}$ percentiles of the hospital volume distribution in 1998 , the last year for which data 


\section{Regionalization Versus Competition in Complex Cancer Surgery}

from all three states in the sample are available.

Given the parameter estimates from the mortality regression it is straightforward to calculate the expected change in mortality. We use the parameter estimates from the mortality regression to predict mortality given the patient's characteristics, but increasing the hospital volume variable (if applicable) to the simulated value after regionalization. In order to make our consumer surplus calculations we then need to translate the change in mortality into a dollar figure. Based on previously published clinical studies (Finlayson et al., 2003), we estimate that each inpatient death associated with Whipple surgery that is avoided implies that approximately one additional qualityadjusted life year (QALY) is gained. Previous U.S. studies assume that a value of US $\$ 100,000$ per QALY is conservative ${ }^{10}$ (Cutler et al., 2003).

In order to calculate consumer surplus we need to calculate the expected change in the price paid for the procedure. To do this we use the estimated impact of changes in concentration on hospital prices from Keeler, Melnick and Zwanziger $(\mathrm{KMZ})($ Keeler et al., 1999). There are several papers that analyze the relationship between hospital concentration and price, but KMZ paper is a well known study from which we could readily construct variables to match their concentration measures. Specifically, we use the estimates from Table 2 (p.79) which imply that the percentage change in price for hospital $\mathrm{j}$ is given by:

$$
\% \Delta P_{j}=.17 H H I+.30\left(\text { share }_{j}-H H I\right) .
$$

Also, in order to calculate the absolute change in price we need a base level price. Proprietary claims data from a nationwide database of self-insured firms with several million covered lives indicates that the average claim paid for the Whipple procedure in 1999 was $\$ 36,154$. This is the figure we use.

There are several limitations of our approach. First, these calculations are "back-of-the envelope." The estimates of the pricing effects of regionalization are based on reduced form regressions using

\footnotetext{
10 Thresholds for cost-effective interventions in the United Kingdom and possibly other developed countries are lower than $\$ 100,000$ per QALY (Rawlins et al., 2004). However, both health care costs and incomes are higher in the U.S. While the direction of the effects estimated in this study may be similar in other countries, policy recommendations should be based on country-specific data.
} 


\section{Regionalization Versus Competition in Complex Cancer Surgery}

data from California from the late 1980s and early 1990s. Our data is from Florida, New Jersey and New York from the late 1980s to the late 1990s. Thus, we are assuming that the same structureconduct-performance relationship that held in California during the period of the KMZ data holds in our data.

Furthermore, KMZ analyze the behavior of hospital level prices. We assume that this aggregate pricing behavior applies to the Whipple procedure; those hospitals that find themselves with fewer competitors for a particular service are more likely to seek price increases. This behavior is even more plausible when hospitals gain bargaining power through state Certificate of Need regulations, which effectively regionalize care by restricting the number of hospitals in a market. Greater hospital pricing power from regionalization may also result from the efforts of the Leapfrog Group, which is a nationwide group aiming to direct patients to high-volume hospitals for several operations, including the Whipple procedure.

We know of only 3 studies that examine the relationship between market concentration and price for a specific procedure at a hospital. These papers examine markets for open heart surgery, angioplasty, and appendectomies (Brooks et al., 1997; Dor et al., 2004; Dor et al., 2005). We cannot rely on any of these studies for estimates of the relationship between market concentration and price, because they instead estimate the relationship between market concentration and the share of rents extracted by the hospital as opposed to the insurer. Therefore, there is no way for us infer a price level from these estimates. However, all 3 studies suggest that procedure-specific concentration has a noticeable impact on prices. For example, the market for appendectomies is more analogous to the Whipple case, in that appendectomies account for fewer than $1 \%$ of all hospital admissions. In this case, the coefficient on the appendectomy-specific Herfindahl index is approximately 0.5 and precisely estimated in all specifications. This finding suggests that a hospital that is a monopolist for appendectomies extracts half of all of the rents available to the hospital and the insurer. The hospital isn't able to extract all of the rents, because it is bargaining with the insurer on a range of services. Nevertheless, the results illustrate that market power in just one procedure can substantially influence prices.

A second limitation is that we do not account for potential cost reductions from regionalization due 


\section{Regionalization Versus Competition in Complex Cancer Surgery}

to economies of scale. There are two reasons for this. First, hospitals do not report procedure-level costs. One can construct an estimate using hospital-level cost-to-charge ratios and the discharge record reported charges. However, the hospital-wide cost-to-charge ratio may be a noisy measure of the true cost-to-charge ratio for services required for the Whipple procedure. Furthermore, even if we had reasonable estimates of the cost changes associated with regionalization, incorporating that information into pricing estimates is problematic. $\mathrm{KMZ}$ do not use cost information in their analysis, so their estimates of price effects incorporate cost consequences of concentration in a reduced form way. It is unclear how one would incorporate cost information to their estimates, unless we were to attempt a more structural approach (e.g. guess at demand elasticities and infer margins and margin changes as a function of concentration). In so far as we do not measure the cost benefits of regionalization, our estimates are lower bound estimates.

Third, we assume that any price changes will not reflect the improved quality of the procedure due to regionalization. We are unaware of any work that has estimated a relationship between hospital quality and hospital prices. In so far as there is a positive correlation between hospital prices and the quality of care, then our estimates of the price increase are biased downward. In addition, the majority of U.S. hospitals are nonprofit, and nonprofit hospitals could redirect increased revenues resulting from pricing power back to the patient population. However, past research finds no significant difference in patient outcomes or benefits to the community between for-profit and nonprofit hospitals (Nicholson et al., 2000; Sloan et al., 2001).

Fourth, it is well known that estimated competition-price relationships are prone to endogeneity bias (Newmark, 2004). For example, if high quality hospitals can command a high price and the presence of a high quality hospital reduces the likelihood that other hospitals will enter, then the coefficient on competition will be biased upwards. The KMZ estimates, like most other structure-conductperformance analysis of hospital pricing, is subject to this potential bias. Work by Gaynor and Vogt (2004) and Capps, Dranove and Saitherwaitte (2004) are less prone to this criticism, but data limitations prevent us from using their estimates in our analysis.

These are significant, but necessary assumptions in order to perform this analysis. The assumptions reflect a combination of data and state of knowledge limitations. For example, it is difficult if not 


\section{Regionalization Versus Competition in Complex Cancer Surgery}

impossible to acquire information on procedure-level, hospital prices for a large sample of privately insured patients. Also, we are unaware of any analysis of the relationship between hospital prices and hospital quality. Given the range of limitations on the pricing side of our analysis, it is best to view the estimates as plausible consequences of regionalization rather than strong predictions of what would actually occur if these regionalization experiments were implemented. However, we provide an important demonstration of the benefits one gains from analyzing regionalization from the perspective of consumer welfare, versus medical outcomes alone.

\section{DATA AND DESCRIPTIVE STATISTICS}

The data for this study come from hospital discharge abstracts provided by the Florida Agency for Health Care Administration for the years 1988 to 1999, the New Jersey Department of Health and Senior Services for 1988 to 1998, and the New York Statewide Planning and Research Cooperative System (SPARCS) for 1989 to 1998. Following previous studies in the literature, we extracted information on all patients with an ICD-9-CM procedure code of 52.7 (radical pancreaticoduodenectomy) (Gordon et al., 1998).

The dataset contains information on 7,709 Whipple procedures performed between the years 1988 and 1999; 3,183 from Florida, 960 from New Jersey, and 3,566 from New York. A total of 431 hospitals and 1,793 surgeons performed the Whipple procedure at least once during the sample period. In 1989 the median hospital performed 2 Whipple surgeries per year; this figure rose to 3 procedures per year by 1998. The largest number of Whipple procedures performed at a hospital in 1989 was 52; by 1998 this figure rose to 132. In all years the median surgeon performed 1 Whipple

procedure per year. The highest volume surgeon in 1989 performed 21 Whipple procedures, and the highest volume surgeon in 1998 performed 40 procedures.

Table 1 provides descriptive statistics on mean characteristics for patients who received the Whipple procedure in 1989, 1994, and 1998. Inpatient mortality fell from $13.7 \%$ in 1989 to $9.0 \%$ in 1994 , but then remained relatively constant through 1998. The casemix severity of patients undergoing Whipple surgery increased slightly over time. Between 1989 and 1998 the average age of the patient population rose from 63.8 years to 65.2 years. The Charlson comorbidity index, a measure of illness 


\section{Regionalization Versus Competition in Complex Cancer Surgery}

severity based on the range of diagnoses in the discharge abstract (Romano et al., 1993), increased from 2.6 to 3.3 in this same time period. The reduction in inpatient mortality in spite of a more severely ill patient population suggests that either technological advances or learning by doing in the performance of the Whipple procedure occurred over time.

In general, inpatient mortality rates decline monotonically with increasing hospital volume and surgeon volume in each year. The correlation between annual surgeon volume and hospital volume in the sample is equal to 0.67 , indicating that high-volume surgeons tend to operate at high-volume hospitals. Therefore, the descriptive statistics do not allow one to independently identify the effect of surgeon versus hospital procedure volume on inpatient death rates. In addition, Table 1 suggests that higher volume hospitals tend to have younger patients. Thus, part of the observed lower mortality rate for high-volume hospitals may be attributable to their propensity to operate on patients who are more able to survive this aggressive procedure. In addition, we wish to test the hypothesis that increased local market competition among hospitals which perform the Whipple procedure may affect outcomes. A multivariate regression is required to examine these issues in more detail.

\section{RESULTS}

\section{5a. Inpatient Mortality Results}

Column 1 of Table 2 provides random effects logit estimates of the determinants of inpatient mortality for Whipple surgery patients. The Florida patient discharge database did not begin to record surgeon identifiers until 1992. Therefore, 731 patients from Florida in the years 1988 to 1991 are not included in the regression sample. In addition, 29 patients in other years from Florida, 33 New Jersey patients, and 25 New York patients were missing surgeon identifiers in other years and are excluded from the mortality regressions.

The parameter estimates indicate that procedure volume at both the hospital and the surgeon level leads to lower probabilities of inpatient mortality. However, increases in surgeon volume lead to reduced mortality at a decreasing rate. These results are precisely estimated and consistent with the hypothesis that learning by doing or organizational scale economies reduce inpatient mortality for the Whipple procedure. 


\section{Regionalization Versus Competition in Complex Cancer Surgery}

We used the estimates in Column 1 to conduct simulations to compare the relative magnitude of each of the volume effects on in-hospital death. We used the characteristics of each patient in the sample to predict their probability of death at particular volume levels. Thus, the predictions were calculated using fixed values of hospital and surgeon volume; but allowing all other explanatory variables to take on their actual values in the sample.

The predictions suggest that if a hospital performs only one Whipple procedure per year (so that surgeon volume is also equal to one), then the expected mortality rate for the patient is $9.4 \%$. If a surgeon who only performs one Whipple procedure per year conducts the operation in a hospital which performs 10 versus 5 Whipple procedures per year, the difference in expected inpatient death rates is $8.6 \%$ versus $9.0 \%$; a 4.4 percent reduction in mortality.

Being treated by a high-volume surgeon reduces inpatient death rates even more. A patient treated by a surgeon who performs only one Whipple procedure per year in a hospital that performs five procedures has an expected inpatient mortality rate of $9.0 \%$. However, if only one surgeon performs all the procedures in a given hospital that treats five patients per year, then the patient's expected inhospital mortality rate falls to $7.1 \%$. In fact, the expected inpatient mortality rate for a surgeon performing one Whipple procedure per year is almost twice as large as the expected rate for a surgeon performing 10 procedures $(8.6 \%$ versus $5.3 \%)$.

Returning to the regression estimates in Table 2, note that the coefficient on the Herfindahl index in Column (1) is imprecisely estimated. Therefore, we find no evidence that increases in market competition in the hospital referral region lead to reduced inpatient mortality. ${ }^{11}$ The coefficients on all of the year dummy variables are negative (relative to patients admitted in 1988 or 1989). However, many of the coefficients are imprecisely estimated. In fact, computation of a Wald statistic suggests that we cannot reject the null hypothesis that the coefficients on the year effects are jointly equal to $0\left(\chi^{2}(10)=8.06, p=0.62\right)$. Therefore, we find no definitive evidence of reductions in inpatient mortality attributable to technological progress for the Whipple procedure. Past studies

${ }^{11}$ In fact, the coefficient on the Herfindahl index is negative, suggesting that competition leads to worse outcomes for Whipple patients. If there is relatively little competition between hospitals for Whipple patients, then the Herfindahl Index may instead capture nonlinear effects of provider volume. In fact, if one excludes hospital and surgeon volume from the regression, the coefficient on the Herfindahl becomes precisely estimated $(\operatorname{coef}=-0.79, \mathrm{t}=$ 


\section{Regionalization Versus Competition in Complex Cancer Surgery}

which have identified technological change in health care have focused on heart disease and have emphasized the benefits of improved catheters, stents, and drugs over time (Cutler et al., 2001). In contrast, the medical literature contains no such comparable advances for Whipple surgery. Therefore, combined skill and experience of the hospital and surgeon remain dominant in explaining outcomes.

A brief examination of the coefficients on the patient characteristic variables in the mortality equation indicates that the estimates are consistent with the clinical prognosis for these patients. Relative to patients under age 60, older patients have a higher probability of death in hospital. Women are less likely to die in hospital than men. Comorbidities tend to increase the probability of inpatient mortality. ${ }^{12}$ Finally, patients treated in teaching hospitals have a substantially lower probability of death than patients treated in non-teaching facilities. The marginal effect implied by the estimated coefficient in the logit regression suggests that the expected death rate for patients treated in teaching hospitals is lower by 2.0 percentage points.

\section{5b. Alternative Specifications}

We estimated a variety of alternative specifications to examine the robustness of the results. Our measure of local market competition was defined based on hospital referral regions, which may be endogenous; increased competition may lead hospitals to draw patients from a larger geographic area, which increases the size and therefore the number of patients in the hospital referral region. We constructed an exogenous measure of hospital competition using distance from the nearest hospital as an instrumental variable for market concentration (Gowrisankaran et al., 2003). The coefficient on this instrumented measure of hospital market concentration was imprecisely estimated in the mortality regression, with a t-statistic $=0.36$. Again we found no evidence that market competition influences outcomes for the Whipple procedure.

The quadratic specification for some of the volume measures suggests that the volume-outcome

\footnotetext{
-2.32).

12 The estimates suggest that diabetes reduces the probability of death in hospital. This result has been identified in past studies using administrative data. The effect is attributed to a lower propensity of coding these conditions for patients at increased risk of death who face multiple highly severe complications while hospitalized (Iezzoni L.I. et al., 1992; Jencks et al., 1988).
} 


\section{Regionalization Versus Competition in Complex Cancer Surgery}

effect "wears off" at higher levels of procedure volume. Given that some recommend regionalization of the Whipple procedure, it would be helpful to determine a cutoff point beyond which volume increases fail to provide meaningful reductions in mortality. We took a closer look at this issue by estimating the determinants of inpatient mortality using categorical dummy variables for procedure volume. We divided the hospital and surgeon volume measures into approximate quartiles, and first tested for significant differences in inpatient mortality relative to the lowest volume quartile. For both hospital and surgeon volume, we found that the coefficient on the highest volume quartile was negative and precisely estimated. ${ }^{13}$ We then divided the highest quartile for both hospital and surgeon volume in half and tested to see whether the highest eighth of the hospital or surgeon volume distribution had lower inpatient mortality rates than the second-highest eighth. In the logit regression of mortality, the coefficient for the highest eighth of the hospital distribution relative to the second-highest eighth is equal to $0.079(\mathrm{t}=1.31)$; and the same coefficient for the surgeon distribution is equal to $-0.216(\mathrm{t}=-0.81)$. These imprecise estimates may be due to the relatively limited sample size of 6,891 patients in the inpatient mortality regressions. That is, the sample size may be insufficient to detect a clinically meaningful difference in mortality rates between the top two eighths of the hospital and physician volume distributions.

Another alternative specification included an interaction term between hospital and surgeon Whipple procedure volume along with the variables specified in the inpatient mortality regression in Table 2. This coefficient was equal to 0.0007 , but imprecisely estimated $(\mathrm{t}=1.62, \mathrm{p}=0.11)$. The estimate provides weak evidence that the beneficial effect of being treated by a high-volume surgeon at a high-volume hospital may be slightly smaller than implied by the combination of the independent effects of hospital and surgeon volume reported in Table 2.

We also experimented with including interaction effects between the hospital and surgeon volume measures and time period. Time periods were defined by splitting the sample into three categories (1988-1991, 1992-1995, and 1996-1999). We examined these interaction terms to test whether the relationship between procedure volume and inpatient mortality became flatter or steeper over time.

${ }^{13}$ These results are available from the author upon request. Not all of the other volume quartiles were precisely estimated. However, we do not discuss these results in detail, because we are primarily interested in examining the volume-outcome effect at the highest levels of procedure volume. 


\section{Regionalization Versus Competition in Complex Cancer Surgery}

None of these interaction terms were precisely estimated.

\section{5c. Consumer Surplus Benefits of Regionalization}

We can use our estimates to assign a financial value to the benefits of regionalization of pancreatic cancer surgery. We first simulated regionalization by re-assigning any patient in a hospital which performed fewer than the three specific cut-off levels $(2,4$ or 6$)$ in a year to the nearest hospital which performed the cut-off level or more procedures in that same year. We then used the coefficient estimates in Table 2 to predict average mortality; and compared these figures to those for the original sample. Because current policy recommendations are focused on concentrating complex surgical procedures at fewer hospitals rather than among fewer surgeons, the simulations assume that the number of Whipple surgeries per surgeon remains constant.

In Table 3, we present the results of our 3 policy experiments. Regionalization of all patients to hospitals performing 2,4, or 6 Whipple procedures per year would reduce the predicted mortality rate in the sample from 9.1 percent to between 8.6 percent (.5 percentage points) to $6.0 \%$ ( 3.1 percentage points). The more restrictive the regionalization rule the larger the mortality reduction. Translating the change in mortality into the value of QALYs per procedure yields an expected increase of $\$ 500$, $\$ 1,800$ and $\$ 3,100$ per patient using the cut-off rules of 2,4 and 6 procedures, respectively.

Regionalized hospitals may use their increased market power to raise prices. Our simulation indicates that regionalizing the Whipple procedure will raise the average Herfindahl index faced by patients in the sample from 0.30 to $.32, .51$ and .63 for the cut-off rules of 2, 4 and 6 procedures, respectively. The increase in the HHI from our policy experiments ranges from the modest to the very large. The associated implied procedure price increases from regionalization are $\$ 1,142$, $\$ 1,618$ and $\$ 1,932$ for the cut-off rules of 2, 4 and 6 procedures, respectively. For the least invasive policy experiment (the 2-procedure cut-off), consumer welfare declines. However, estimated consumer surplus increases modestly (\$182) for the 4-procedure cut-off experiment and increased substantially $(\$ 1,168)$ in the 6-procedure cut-off rule. Thus, in our simulations regionalization can increase consumer surplus, but the direction and magnitude of the change in consumer surplus is sensitive to the regionalization rule. It is also important to recognize that the positive correlation we find between the severity of the regionalization rule and the benefits to consumers is a function of the concavity of the price response to concentration and the convexity of the outcome response to 


\section{Regionalization Versus Competition in Complex Cancer Surgery}

increase volume. While we believe we chose a sensible price/-concentration relationship from the literature, different estimated price/concentration relationships may have different welfare implications for regionalization.

Regionalization also increases the distance that patients must travel to the hospital - $\mathrm{a}$ cost to consumers that we did not incorporate into the analysis. Relative to the cost of the Whipple procedure and the magnitude of the QALY gains, the increases in travel costs are modest. However, this may not be the case for many other procedures that might be considered for regionalization.

\section{CONCLUSIONS}

Past studies identifying a cross-sectional association between higher procedure volume and lower inpatient mortality have been used to recommend minimum volume standards or regionalization of complex surgeries. These minimum volume standards have been incorporated into state Certificate of Need regulations for a number of procedures. In addition, The Leapfrog Group, a large coalition of major U.S. employers and health care purchasers, is encouraging employees and customers to select high quality hospitals for care; where quality is measured in part by the volume of procedures performed each year.

We perform three regionalization experiments in order to assess the impact of regionalization on outcomes and consumer surplus. The lessons of these experiments are three fold. First, regionalization can increase consumer surplus but the benefits may be substantially less than implied by examining only the outcome side of the equation. Second, which is related to the point above, modest changes in outcomes due to regionalization may lead to decreases in consumer surplus. Third, before any regionalization policy is implemented, a deep and precise understanding of the nature of both outcome/volume and price/competition relationships is needed.

These results suggest that blanket statements to either regionalize all surgical procedures, or promote unregulated competition for all surgical procedures in order to improve social welfare are incorrect.

Government efforts to reduce the proliferation of providers can increase consumer welfare, but only 


\section{Regionalization Versus Competition in Complex Cancer Surgery}

in cases where price competition is preserved. A significant reduction in hospital competition may very well erase the gains in consumer welfare from regionalization. The optimal policy will need to assess both the mortality and cost implications of regionalization in order to determine the appropriate intervention. It is important to recognize that our findings are based on some very simple back of the envelope calculations, which employ a number of large assumptions and can only be interpreted as suggestive of the impact of regionalization on consumer surplus.

This paper as a first attempt to incorporate quality and price effects of procedure consolidation into a single analysis. Further work is clearly needed. In particular, estimation of a structural model of hospital pricing under quality and location differentiation in which quality is determined in a learning-by-doing framework would clarify our understanding of the welfare implications of regionalization. While the construction and estimation of such a model is a significant challenge, it strikes us as worthwhile, given the current calls from the medical community and employers to regionalize procedures. 
Table 1: Trends in Patient Characteristics and Charges by Whipple Volume (selected years)

\begin{tabular}{|c|c|c|c|c|c|c|c|}
\hline \multicolumn{8}{|c|}{ Year $=1989 ; \mathrm{N}=518$} \\
\hline & \multirow{2}{*}{ Total } & \multicolumn{3}{|c|}{ Hospital Volume } & \multicolumn{3}{|c|}{ Surgeon Volume } \\
\hline & & $1-3$ & $4-9$ & $10+$ & 1 & $2-4$ & $5+$ \\
\hline $\begin{array}{c}\text { In-hospital } \\
\text { Mortality (\%) }\end{array}$ & 13.7 & 18.0 & 10.9 & 4.5 & 20.9 & 8.1 & 4.8 \\
\hline Age & 63.8 & 64.6 & 63.6 & 61.4 & 62.7 & 64.2 & 61.6 \\
\hline $\begin{array}{l}\text { Charlson } \\
\text { Index }\end{array}$ & 2.6 & 2.3 & 2.9 & 3.0 & 2.2 & 2.8 & 3.0 \\
\hline \multicolumn{8}{|c|}{ Year $=1994 ; \mathrm{N}=720$} \\
\hline & \multirow[b]{2}{*}{ Total } & \multicolumn{3}{|c|}{ Hospital Volume } & \multicolumn{3}{|c|}{ Surgeon Volume } \\
\hline & & $1-3$ & $4-9$ & $10+$ & 1 & $2-4$ & $5+$ \\
\hline $\begin{array}{c}\text { In-hospital } \\
\text { Mortality (\%) }\end{array}$ & 9.0 & 13.8 & 7.9 & 4.3 & 11.0 & 11.7 & 3.3 \\
\hline Age & 64.7 & 65.5 & 64.8 & 63.5 & 64.5 & 65.5 & 64.1 \\
\hline $\begin{array}{l}\text { Charlson } \\
\text { Index }\end{array}$ & 3.3 & 3.2 & 3.1 & 3.7 & 3.3 & 3.1 & 3.7 \\
\hline \multicolumn{8}{|c|}{ Year $=1998 ; \mathrm{N}=1062$} \\
\hline & \multirow[b]{2}{*}{ Total } & \multicolumn{3}{|c|}{ Hospital Volume } & \multicolumn{3}{|c|}{ Surgeon Volume } \\
\hline & & $1-3$ & $4-9$ & $10+$ & 1 & $2-4$ & $5+$ \\
\hline $\begin{array}{c}\text { In-hospital } \\
\text { Mortality (\%) }\end{array}$ & 8.9 & 16.5 & 11.0 & 3.6 & 11.9 & 11.9 & 4.8 \\
\hline Age & 65.2 & 66.4 & 66.9 & 63.5 & 65.1 & 66.0 & 64.7 \\
\hline $\begin{array}{l}\text { Charlson } \\
\text { Index }\end{array}$ & 3.3 & 3.2 & 3.5 & 3.3 & 3.4 & 3.1 & 3.4 \\
\hline
\end{tabular}




\section{Table 2: Multilevel Logit Random Effects Regression of Mortality Determinants}

\begin{tabular}{|c|c|c|}
\hline & Coefficient & t-statistic \\
\hline Annual Hospital Volume & -0.011 & $(-1.69)$ \\
\hline Annual Hospital Volume* NJ & -0.218 & $(-3.06)$ \\
\hline Annual Surgeon Volume & -0.072 & $(-2.42)$ \\
\hline Annual Surgeon Volume ${ }^{2}$ & 0.001 & $(1.33)$ \\
\hline Herfindahl Index & -0.392 & $(-1.08)$ \\
\hline 1990 & -0.529 & $(-1.96)$ \\
\hline 1991 & -0.398 & $(-1.56)$ \\
\hline 1992 & -0.162 & $(-0.71)$ \\
\hline 1993 & -0.151 & $(-0.67)$ \\
\hline 1994 & -0.360 & $(-1.57)$ \\
\hline 1995 & -0.358 & $(-1.55)$ \\
\hline 1996 & -0.262 & $(-1.15)$ \\
\hline 1997 & -0.392 & $(-1.72)$ \\
\hline 1998 & -0.238 & $(-1.06)$ \\
\hline 1999 & -0.479 & $(-1.63)$ \\
\hline Age $60-69$ & 0.455 & $(3.21)$ \\
\hline Age $70-79$ & 1.024 & $(7.52)$ \\
\hline Age 80 & 1.578 & $(8.75)$ \\
\hline Female & -0.287 & $(-3.03)$ \\
\hline Myocardial Infarction & -0.353 & $(-0.82)$ \\
\hline Peripheral vascular disease & 0.338 & $(1.10)$ \\
\hline Chronic pulmonary disease & 0.055 & $(0.36)$ \\
\hline Mild liver disease & 1.009 & $(3.15)$ \\
\hline Mild/moderate diabetes & -0.508 & $(-3.41)$ \\
\hline Diabetes with chronic complications & -0.883 & $(-2.71)$ \\
\hline Renal disease & 3.268 & $(9.32)$ \\
\hline Moderate/severe liver disease & 2.123 & $(5.46)$ \\
\hline Extra-hepatic bile duct cancer & -0.240 & $(-1.98)$ \\
\hline Duodenal cancer & 0.068 & $(0.37)$ \\
\hline Benign pancreatic disease & -0.887 & $(-3.32)$ \\
\hline Other indication for Whipple & -0.060 & $(-0.39)$ \\
\hline Length of stay & 0.005 & $(2.46)$ \\
\hline Teaching hospital & -0.344 & $(-2.39)$ \\
\hline FL & -0.141 & $(-0.87)$ \\
\hline NJ & 0.700 & $(2.74)$ \\
\hline Constant & -2.022 & $(-7.56)$ \\
\hline $\mathrm{N}$ & \multicolumn{2}{|c|}{6778} \\
\hline
\end{tabular}




\section{Regionalization Versus Competition in Complex Cancer Surgery}

Table 3: Regionalization Policy Experiment

\begin{tabular}{|l|cccccc|}
\hline $\begin{array}{l}\text { Regionalization } \\
\text { Rule }\end{array}$ & $\begin{array}{c}\text { Decrease in } \\
\text { Average } \\
\text { Mortality }\end{array}$ & $\begin{array}{c}\text { \$ Value of } \\
\text { QALY } \\
\text { Impact per } \\
\text { Patient }\end{array}$ & $\begin{array}{c}\text { Change in } \\
\text { HHI }\end{array}$ & $\begin{array}{c}\text { Increase in } \\
\text { Average Price } \\
\text { (percentage } \\
\text { increase in } \\
\text { price) }\end{array}$ & $\begin{array}{c}\text { Increase in } \\
\text { price that } \\
\text { makes } \\
\text { CS }=0\end{array}$ & $\begin{array}{c}\text { Increase in } \\
\text { Average } \\
\text { Distance to } \\
\text { Admitting } \\
\text { Hospital }\end{array}$ \\
\hline $\begin{array}{l}\text { Hospitals }>=2 \\
\text { procedures }\end{array}$ & 0.5 & $\$ 500$ & .02 & $\begin{array}{c}\$ 1142 \\
(3.2 \%)\end{array}$ & $1.4 \%$ & 2.64 \\
$\begin{array}{l}\text { Hospitals }>=4 \\
\text { procedures } \\
\text { Hospitals }>=6 \\
\text { procedures }\end{array}$ & 1.8 & $\$ 1800$ & .21 & $\begin{array}{c}\$ 1618 \\
(4.5 \%)\end{array}$ & $5.0 \%$ & 14.72 \\
\end{tabular}




\section{Regionalization Versus Competition in Complex Cancer Surgery}

\section{REFERENCES}

Birkmeyer, J. D., Finlayson, S. R. G., Tosteson, A. N. A., Sharp, S. M., Warshaw, A. L., and Fisher, E. S. (1999), 'Effect of hospital volume on in-hospital mortality with pancreaticoduodenectomy', Surgery, 125(3): 250-256.

Birkmeyer, J. D., Siewers, A. E., Finlayson, S. R., Stukel, T. A., Lucas, F. L., Batista, I., Welch, H. G., and Wennberg, D. E. (2002), 'Hospital volume and surgical mortality in the United States', N Engl J Med, 346(15): 1128-1137.

Brooks, J. M., Dor, A., and Wong, H. S. (1997), 'Hospital-insurer bargaining: an empirical investigation of appendectomy pricing', J Health Econ., 16(4): 417-434.

Capps, C., Dranove, D., and Satterthwaite, M. (2004), 'Competition and market power in option demand markets', The RAND Journal of Economics, 34(4): 737-763.

Cutler, D. M. and Huckman, R. S. (2003), 'Technological development and medical productivity: the diffusion of angioplasty in New York state', Journal of Health Economics, 22(2): 187217.

Cutler, D. M. and McClellan, M. B. (2001), 'Is technological change in medicine worth it?', Health Affairs, 20(5): 11-29.

Department of Justice and Federal Trade Commission (2004), 'Improving health care: a dose of competition: a report by the Federal Trade Commission and the Department of Justice'.

Dor, A., Grossman, M., and Koroukian, S. M. (2005), 'Hospital transaction prices and managedcare discounting for selected medical technologies', American Economic Review, 94(2): 352-356.

Dor, A., Koroukian, S. M., and Grossman, M. (2004), 'Managed care discounting: evidence from the MarketScan database', Inquiry, 41(2): 159-169.

Finlayson, E. V. and Birkmeyer, J. D. (2003), 'Effects of hospital volume on life expectancy after selected cancer operations in older adults: a decision analysis', J.Am.Coll.Surg., 196(3): 410-417.

Gaynor, M., Seider, H., and Vogt, W. B. (2005), 'The Volume-Outcome Effect, Scale Economies, and Learning by Doing', American Economic Review, 95(2): 243-247. 


\section{Regionalization Versus Competition in Complex Cancer Surgery}

Gaynor, M. and Vogt, W. B. (2004), 'Competition among hospitals', The RAND Journal of Economics, 34(4): 764-785.

Goldberger, A. S. (1991), 'A Course in Econometrics'.

Gordon, T. A., Bowman, H. M., Bass E.B., Lillemoe, K. D., Yeo, C. J., Heitmiller, R. F., Choti, M. A., Burleyson, G. P., Hsieh, G., and Cameron, J. L. (1999), 'Complex gastrointestinal surgery: Impact of provider experience on clinical and economic outcomes', J Am Coll Surg, 189(1): 46-56.

Gordon, T. A., Bowman, H. M., Tielsch, J. M., Bass, E. B., Burleyson, G. P., and Cameron, J. L. (1998), 'Statewide regionalization of pancreaticoduodenectomy and its effect on inhospital mortality', Annals of Surgery, 228(1): 71-78.

Gowrisankaran, G., Ho, V., and Town, R. J. (2006), 'Causality, Learning and Forgetting in Surgery', Working Paper, http://www.ftc.gov/be/healthcare/wp/04_Gowrisankaran_CausalityLearningandForgettin ginSurgery.pdf.

Gowrisankaran, G. and Town, R. (2003), 'Competition, payers, and hospital quality', Health Services Research, 38(6): 1403-1421.

Greene W.H. (2000), 'The classical multiple linear regression model: specification and estimation', 4th(6): 210-270.

Hausman, J. (1978), 'Specification tests in econometrics', Econometrica, 46: 1251-1271.

Ho V. (2002), 'Learning and the evolution of medical technologies: The diffusion of coronary angioplasty', Journal of Health Economics, 21(5): 873-885.

Ho V. and Hamilton B.H. (2000), 'Hospital mergers and acquisitions: Does market consolidation harm patients?', Journal of Health Economics, 19(5): 767-791.

Ho, V. and Heslin, M. J. (2002), 'Effect of hospital volume and experience on in-hospital mortality for pancreaticuduodenectomy', Annals of Surgery, 237(4): 509-514.

Huckman, R. S. (2006), 'Hospital integration and vertical consolidation: An analysis of acquisitions in New York State', Journal of Health Economics, 25(1): 58-80.

Hughes, R. G., Garnick, D. W., Luft, H. S., McPhee, S. J., and Hunt, S. S. (1988), 'Hospital volume and patient outcomes: The case of hip fracture patients', Medical Care, 26(11): 1057-1067. 


\section{Regionalization Versus Competition in Complex Cancer Surgery}

Iezzoni L.I., Foley, S. M., Daley, J., Hughes, J., Fisher, E. S., and Heeren, T. (1992), 'Comorbidities, complications, and coding bias. Does the number of diagnosis codes matter in predicting in-hospital mortality?', The Journal of the American Medical Association, 267(16): 2197-2203.

Jencks, S. F., Williams, D. K., and Kay, T. L. (1988), 'Assessing hospital-associated deaths from discharge data', The Journal of the American Medical Association, 260: 2240-2246.

Keeler, E. B., Melnick, G., and Zwanziger, J. (1999), 'The changing effects of competition on non-profit and for-profit hospital pricing behavior', Journal of Health Economics, 18(1): 69-86.

Kessler, D. P. and McClellan, M. B. (2000), 'Is hospital competition socially wasteful?', The Quarterly Journal of Economics, 115(2): 577-615.

Luft, H. S., Bunker, J., and Enthoven, A. (1979), 'Should operations be regionalized? An empirical study of the relation between surgical volume and mortality', The New England Journal of Medicine, 301(25): 1364-1369.

Newmark, C. M. (2004), 'Price-concentrations studies: there you go again.', Prepared for the DOJ/FTC merger workshop, concentration and market shares panel.

Nicholson, S., Pauly, M. V., Burns, L. R., Baumritter, A., and Asch, D. A. (2000), 'Measuring community benefits provided by for-profit and nonprofit hospitals', Health Affairs, 19(6): $168-177$.

Pauly, M. V. (2004), 'Competition in medical services and the quality of care: concepts and history', International Journal of Health Care Finance and Economics, 4: 113-130.

Phillips, K. A., Luft, H. S., and Ritchie, J. L. (1995), 'The association of hospital volumes of percutaneous transluminal coronary angioplasty with adverse outcomes, length of stay, and charges in California', Medical Care, 33(5): 502-514.

Rawlins, M. D. and Culyer, A. J. (2004), 'National Institute for Clinical Excellence and its value judgments', British Medical Journal, 329(7459): 224-227.

Romano, P. S., Roos, L. L., and Jollis, J. G. (1993), 'Adapting a clinical comorbidity index for use with ICD-9-CM administrative data: Differing perspectives', Journal of Clinical Epidemiology, 46(10): 1075-1079.

Sloan, F. A., Picone, G. A., Taylor Jr., D. H., and Chou, S.-Y (2001), 'Hospital ownership and cost and quality of care: is there a dime's worth of difference?', Journal of Health Economics, 20(1): 1-22. 


\section{Regionalization Versus Competition in Complex Cancer Surgery}

Solow, R. M. (1957), 'Technical change and the aggregate production function', The Review of Economics and Statistics, 39(3): 312-320.

Spence, A. M. (1981), 'The learning curve and competition', Bell Journal of Economics, 12(1): 49-70.

Sturm, R. (1999), 'Cost and quality trends under managed care: Is there a learning curve in behavioral health carve-out plans?', Journal of Health Economics, 18(5): 593-604.

Williamson, O. E. (1968), 'Economies as an antitrust defense: The welfare tradeoffs.', The American Economic Review, 58(1): 18-36.

Wong, H. S., McNamara, P., and Greenburg, W. (2004), 'Provider competition and health care quality: challenges and opportunities for research', International Journal of Health Care Finance and Economics, 4: 99-111.

Wooldridge, J. M. (2000), 'Introductory Econometrics: A Modern Approach'. 